Article

\title{
Coordination Nature of 4-Mercaptoaniline to Sn(II) Ion: Formation of a One Dimensional Coordination Polymer and Its Decomposition to a Mono Nuclear Sn(IV) Complex
}

\author{
Eon S. Burkett and Tasneem A. Siddiquee * \\ Boswell Science Complex, Department of Chemistry, Tennessee State University, \\ 3500 John A. Merritt Blvd., Nashville, TN 37209, USA; E-Mail: eon.burkett@gmail.com \\ * Author to whom correspondence should be addressed; E-Mail: tsiddiqu@tnstate.edu; \\ Tel.: +1-615-963-5337; Fax: +1-615-963-5326.
}

External Editor: Duncan Gregory

Received: 6 August 2014; in revised form: 13 November 2014 / Accepted: 14 November 2014 / Published: 8 December 2014

\begin{abstract}
The coordination of the bifunctional ligand 4-mercaptoaniline with aqueous tin(II) metal ion was studied. A coordination polymer was synthesized when an aqueous solution of $\mathrm{SnCl}_{2}$ was treated with 4-MA. The crystalline material is stable under atmospheric conditions retaining its oxidation state. However, when submerged in a solution saturated with oxygen, the compound oxidizes to a mononuclear tin(IV) complex. Both the compounds were characterized by single crystal X-ray diffraction studies. Although the structure of the tin(IV) complex was previously reported, crystal structure of this compound was redetermined.
\end{abstract}

Keywords: tin(II); tin(IV); coordination complex; polymer; metal sulfide; 4-Aminothiophenol; mercaptoaniline; aqueous; synthesize; redox

\section{Introduction}

Recently, we have investigated various separation techniques in order to isolate metal ions from aqueous waste streams. Methods that can yield recyclable treated material are of interest. One such technique involves the use of 4-mercaptoaniline (4-MA) as a precipitant. The precipitated material from this method can be recycled as metal sulfides. 
4-MA is commonly used to conduct surface enhanced Raman spectroscopy (SERS) [1], as the metal-binding terminal end of conductive nanowires [2], and to synthesize gold nanoparticles [3]. Sulfur serves as a "soft" ligand (base) with affinity for "soft" metals (acids), according to hard soft acid base (HSAB) theory. Sulfur can coordinate both in terminal and bridging fashion to a metal center [4]. We are exploring the feasibility of using 4-MA as a precipitating agent to treat aqueous metal ion waste streams. 4-MA is known to exist as a zwitterion in both solid and pure liquid forms [5].

Tin is a group 14 metal with common oxidation states of +2 and +4 . It finds many applications in fuel cells [6], batteries [7] and photovoltaics [8] to chemical sensors [9], semiconducting nanowires [10], and window coatings [11]. Many types of catalysis utilizing tin species have been reported [12], including hydrogenations [13], cross-coupling reactions [14], oxidation of carbon monoxide [15] and ethanol [16] and the reduction of carbon dioxide [17] and $\mathrm{NO}_{x}$ [18]. Tin oxides [19] and tin sulfides [20] are well known and characterized for their structures and activities.

Previously Eichhöfer and co-workers reported the synthesis of a one dimensional polymer compound (2) that was formed by one tin(II) and two thiophenol units per monomer [21]. One thiolate bridges the tin backbone while the other "sticks out" from the chain. This synthesis was carried out in dimethyl ether (DME) and $\mathrm{PhSSiMe}_{3}$ was used as a source of thiophenol moiety. Our studies on separation techniques demand execution in water, hence we have studied the coordination of tin(II) in aqueous medium with ethanolic 4-MA under ambient conditions. We also examined the coordination of tin(II) in nonaqueous solution under ambient conditions. Studies with tin(IV) and thiophenols have also been carried out in nonaqueous medium at elevated temperature, using the disulfide form of MA [22,23]. Complexes of inorganic or organic mercury and 4-MA have been synthesized, yielding polymeric substances [24].

We studied the application of 4-MA as a mercury(II) precipitant using cold vapor atomic absorption spectroscopy (CVAAS). We suspected that there could be some chemical interference due to coordination of excess 4-MA (from mercury treatment) to tin(II) used in CVAAS. The method for mercury analysis using this technique requires the use of tin(II) ion to reduce mercury(II) to mercury(0) followed by atomic absorption spectroscopy. Since tin(II) is similarly "soft" as mercury(II) we anticipated that it was a good candidate for complexation with 4-MA. We were able to remove over $98 \%$ of tin(IV) from a $6000 \mathrm{ppm}$ synthetic waste stream. In this article we report a study on the coordination nature of tin(II) chloride with 4-MA in ambient conditions.

\section{Results and Discussion}

The tin solution used in CVAAS is acidic and hence, we treated $\mathrm{SnCl}_{2}$ in $10 \% v / v \mathrm{HCl}$ with ethanolic 4-MA solution. This yielded no precipitation. However, when an acid-free solution of $\mathrm{SnCl}_{2}$ was treated with ethanolic 4-MA, precipitation did occur. We were also interested in learning if tin(II) can be oxidized to tin(IV) when coordinating with 4-MA and thereby making tin(II) unavailable for the reduction of mercury(II).

When colorless aqueous solution of $\mathrm{SnCl}_{2}$ is treated with ethanolic 4-MA, solution color changes to yellow. If this solution is shaken, microcrystalline material begins to form. Diffraction quality crystals can be formed by taking the un-disturbed solution and storing it overnight in the fridge. It must be noted that in every synthesis of tin(II) complex attempted, both tin(II) and tin(IV) complexes formed. Single 
crystal X-ray diffraction analysis of such crystals revealed the polymeric structure of compound $\mathbf{1}$ and tetrahedral mononuclear compound 2. Table 1 contains the crystallographic data of compounds $\mathbf{1}$ and $\mathbf{2}$.

Table 1. Crystallographic data for compound 1 and 2.

\begin{tabular}{|c|c|c|}
\hline Compound & 1 & 2 \\
\hline Empirical formula & $\mathrm{C}_{12} \mathrm{H}_{15} \mathrm{ClN}_{2} \mathrm{OS}_{2} \mathrm{Sn}$ & $\mathrm{C}_{24} \mathrm{H}_{26} \mathrm{Cl}_{2} \mathrm{~N}_{4} \mathrm{~S}_{4} \mathrm{Sn}$ \\
\hline Formula weight & $421.52 \mathrm{~g} \mathrm{~mol}^{-1}$ & $688.32 \mathrm{~g} \mathrm{~mol}^{-1}$ \\
\hline Temperature & $273(2) \mathrm{K}$ & $273(2) \mathrm{K}$ \\
\hline Wavelength & $0.71075 \AA$ & $0.71075 \AA$ \\
\hline Crystal system & Monoclinic & Monoclinic \\
\hline Space group & $\mathrm{P} 2(1) / \mathrm{c}$ & $\mathrm{C} 2 / \mathrm{c}$ \\
\hline Unit cell dimensions & $\begin{array}{c}\mathrm{a}=17.328(14) \AA ; \alpha=90^{\circ} \\
\mathrm{b}=12.160(9) \AA ; \beta=95.404(1)^{\circ} \\
\mathrm{c}=7.253(6) \AA ; \gamma=90^{\circ}\end{array}$ & $\begin{array}{c}\mathrm{a}=31.03(2) \AA ; \alpha=90^{\circ} \\
\mathrm{b}=7.961(6) \AA ; \beta=97.377(9)^{\circ} \\
\mathrm{c}=11.718(9) \AA ; \gamma=90^{\circ}\end{array}$ \\
\hline Volume & $1521(2) \AA^{3}$ & $2871(4) \AA^{3}$ \\
\hline $\mathrm{Z}$ & 4 & 4 \\
\hline Density (calculated) & $1.840 \mathrm{Mg} / \mathrm{m}^{3}$ & $1.593 \mathrm{Mg} / \mathrm{m}^{3}$ \\
\hline Absorption coefficient & $2.122 \mathrm{~mm}^{-1}$ & $1.388 \mathrm{~mm}^{-1}$ \\
\hline$F(000)$ & 832 & 1384 \\
\hline Crystal size & $0.29 \times 0.16 \times 0.03 \mathrm{~mm}^{3}$ & $0.23 \times 0.15 \times 0.14 \mathrm{~mm}^{3}$ \\
\hline Theta range for data collection & 2.049 to $27.418^{\circ}$ & 2.643 to $27.482^{\circ}$ \\
\hline Index ranges & $\begin{array}{c}-20 \leq h \leq 22,-15 \leq k \leq 15 \\
-9 \leq l \leq 9\end{array}$ & $\begin{array}{c}-40 \leq h \leq 38,-10 \leq k \leq 10 \\
-15 \leq l \leq 15\end{array}$ \\
\hline Reflections collected & 8800 & 11610 \\
\hline Independent reflections & $3443[R($ int $)=0.0726]$ & $3281[R($ int $)=0.0427]$ \\
\hline $\begin{array}{l}\text { Completeness to } \\
\text { theta }=27.418^{\circ}\end{array}$ & $98.9 \%$ & $99.9 \%$ \\
\hline Absorption correction & Semi-empirical from equivalents & Semi-empirical from equivalents \\
\hline Max. and min. transmission & 1.00 and 0.870 & 1.000 and 0.829 \\
\hline Refinement method & Full-matrix least-squares on $F^{2}$ & Full-matrix least-squares on $F^{2}$ \\
\hline Data/restraints/parameters & $3443 / 12 / 200$ & $3281 / 0 / 211$ \\
\hline Goodness-of-fit on $F^{2}$ & 1.064 & 1.074 \\
\hline Final $\mathrm{R}$ indices $[I>2 \operatorname{sigma}(I)]$ & $R 1=0.0536, \mathrm{w} R 2=0.1091$ & $R 1=0.0321, \mathrm{w} R 2=0.0798$ \\
\hline $\mathrm{R}$ indices (all data) & $R 1=0.0974, \mathrm{w} R 2=0.1091$ & $R 1=0.0373, \mathrm{w} R 2=0.0832$ \\
\hline Extinction coefficient & $\mathrm{n} / \mathrm{a}$ & $\mathrm{n} / \mathrm{a}$ \\
\hline Largest diff. peak and hole & 0.806 and $-1.030 \mathrm{e} . \AA^{-3}$ & 0.465 and -0.838 e. $\AA^{-3}$ \\
\hline
\end{tabular}

The 1-D coordination polymer of tin and 4-MA can also be synthesized by layering ethanolic 4-MA on top of anhydrous $\mathrm{SnCl}_{2}$. This yields better crystals than the aqueous route. Compound $\mathbf{1}$ can be converted to complex 2 by dissolving complex $\mathbf{1}$ in acetone and bubbling air through the solution overnight (Scheme 1). Whether simple stoichiometric variation could lead to the formation of $\mathbf{2}$ was also investigated. When anhydrous $\mathrm{SnCl}_{2}$ is treated by layering ethanolic 4-MA in a 4:1 ligand to metal ratio and the material was allowed to crystallize overnight in the fridge, both compounds $\mathbf{1}$ and $\mathbf{2}$ form. Compound 2 can also be synthesized by treating $\mathrm{SnCl}_{4} \cdot 5 \mathrm{H}_{2} \mathrm{O}$ in the same manner with 4-MA (Scheme 1). 
Scheme 1. Synthesis of one dimensional coordination polymer (followed by its subsequent decomposition to the tin(IV) complex).

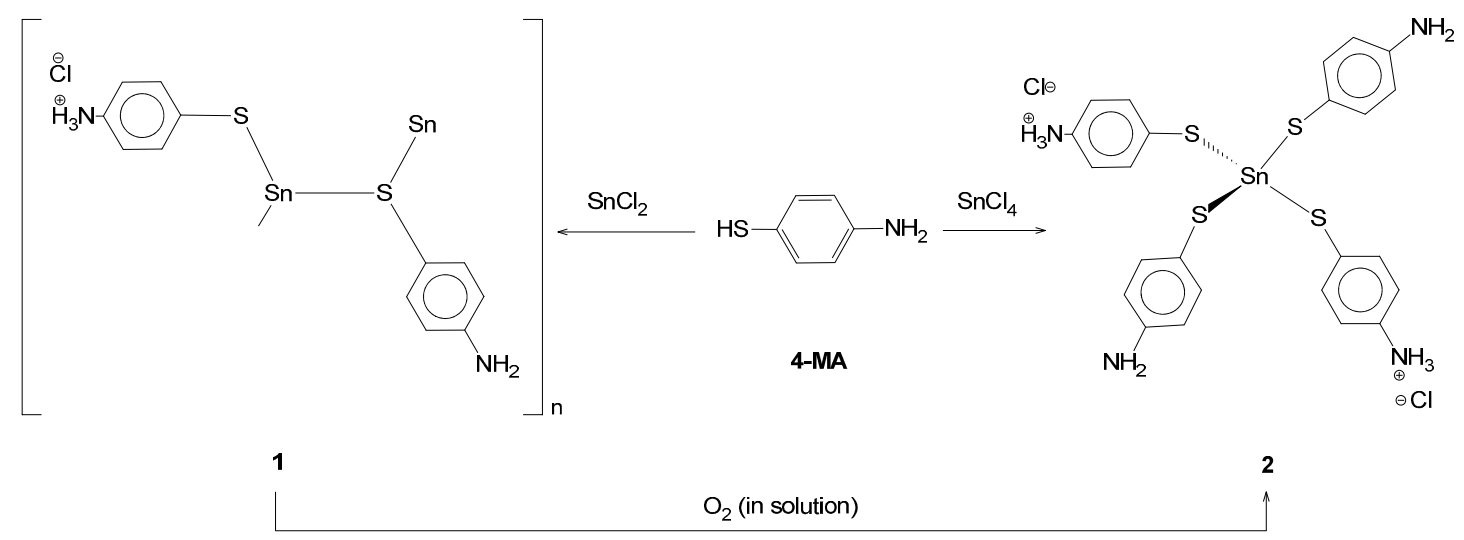

For the 1-D polymeric tin(II) complex we report trigonal pyramidal geometry around the tin(II) center. The polymer backbone of the tin(II) complex is composed of alternating tin-sulfur bonds in a "zipper" shape (when viewed along the $\mathrm{b}$ axis). The bonds between the tin center and bridging sulfur are two distinct lengths; the "primary" $\mu$ sulfur-tin bond length is 2.594(3) $\AA$ and the "secondary" $\mu$ sulfur-tin bond length is 2.702(2) $\AA$ (Table 2). These bridging ligands each have a terminal amine group. Each tin(II) center has an additional terminal 4-MA ligand. Unlike the bridging ligands, the terminal amine groups of the terminal ligands are protonated and paired with chloride counter anions. The distance between tin and sulfur of two neighboring strands is 3.778 A. As mentioned, Eichhöfer's group previously synthesized a tin-containing 1-D coordination polymer which utilized thiophenol as the bridge [21] between two neighboring tin. They also report distorted trigonal pyramidal geometry around tin. The S1-Sn1 bond length in this compound was 2.518(2) $\AA$, the S2-Sn1 bond length was 2.577(2) $\AA$ and the S2'-Sn1 bond length was 2.731(2) $\AA$. The reported S1-Sn1-S2 angle is $77.16(6)^{\circ}$, the $\mathrm{S} 1-\mathrm{Sn} 1-\mathrm{S} 22^{\prime}$ angle is $92.68(6)^{\circ}$, and the $\mathrm{S} 2-\mathrm{Sn} 1-\mathrm{S} 22^{\prime}$ angle is $87.58(5)^{\circ}$.

Table 2. Selected bond distance and bond angles for compounds $\mathbf{1}$ and $\mathbf{2 .}$

\begin{tabular}{cl|cc}
\hline \multicolumn{1}{c|}{ Bond lengths, $\AA$} \\
\hline $\mathrm{Sn}(1)-\mathrm{S}(1)$ & $2.563(3)$ & $\mathrm{Sn}(1)-\mathrm{S}(1)$ & $2.399(1)$ \\
\hline $\mathrm{Sn}(1)-\mathrm{S}(2)$ & $2.702(2)$ & $\mathrm{Sn}(1)-\mathrm{S}(2)$ & $2.395(1)$ \\
\hline \multicolumn{5}{c}{ Bond angles, ${ }^{\circ}$} \\
\hline $\mathrm{S}(1)-\mathrm{Sn}(1)-\mathrm{S}(2)$ & $92.28(6)$ & $\mathrm{S}(2)-\mathrm{Sn}(1)-\mathrm{S}(1)$ & $101.73(5)$ \\
\hline
\end{tabular}

Wang and co-workers have previously synthesized and characterized compound 2 [Sn(4-SC6 $\left.\mathrm{H}_{4} \mathrm{NH}_{2}\right)_{2}\left(4-\mathrm{SC}_{6} \mathrm{H}_{4} \mathrm{NH}_{3}\right)_{2} \mathrm{Cl}_{2}$ ] [25]. Complex 2 is a mono-nuclear compound with tetrahedral coordination around tin. Two 4-MA moieties contain terminal amine groups and two of them contain terminal ammonium groups with associated chloride counter ions. The Sn-S2 bond length (for each amine-terminal ligand) is 2.3955(12) $\AA$; the $\mathrm{Sn}-\mathrm{S} 1$ length (for each ammonium-terminal ligand) is $2.3989(13) \AA$. The sulfur-tin-sulfur angle in the asymmetric unit is $101.73(5)^{\circ}$. Figure $1 \mathrm{a}, \mathrm{b}$ are the ORTEP diagrams of compound $\mathbf{1}$ and compound $\mathbf{2}$, respectively. 
Figure 1. (a) ORTEP diagram of Sn (II) containing one dimensional polymer (1) and (b) ORTEP diagram of Sn(IV) containing mononuclear complex (2).

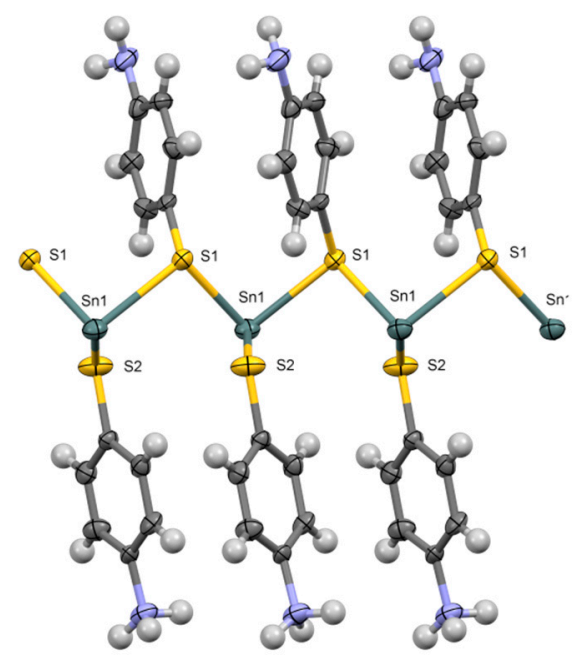

(a)

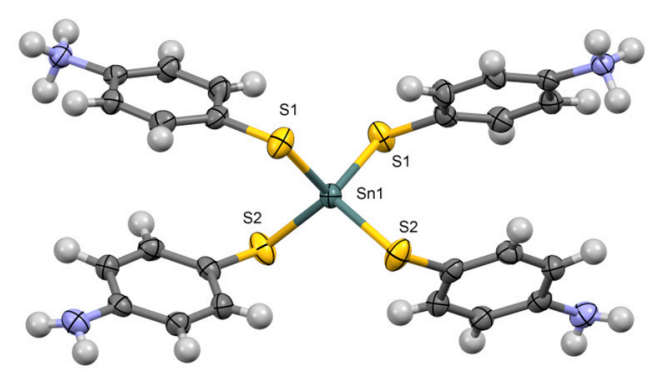

(b)

\section{Experimental Section}

\subsection{General}

Both complex 1 and complex 2 were synthesized under ambient conditions. Reagents were obtained commercially and used without further purification. XRD data were collected on a Rigaku (The Woodlands, TX, USA) XtaLAB mini. Infrared spectra were recorded on a Thermo Scientific Nicolet (Madison, WI, USA) iS10 with smart iTR accessory.

\subsection{Synthesis of $\left[\left\{\mathrm{Sn}\left(\mu-4-\mathrm{C}_{6} \mathrm{H}_{4} \mathrm{NH}_{3} \mathrm{~S}\right)\left(4-\mathrm{C}_{6} \mathrm{H}_{4} \mathrm{NH}_{2} \mathrm{~S}\right)\right\} \mathrm{Cl} \cdot \mathrm{H}_{2} \mathrm{O}\right]_{n}$}

The tin(II) complex (1) was prepared by two routes.

Route 1: $0.0759 \mathrm{~g}(0.4 \mathrm{mmol}) \mathrm{SnCl}_{2}$ was dissolved in $1 \mathrm{~mL}$ of deionized water to which $0.1056 \mathrm{~g}$ ( $0.8 \mathrm{mmol})$ 4-MA dissolved in $1.5 \mathrm{~mL}$ of ethanol was added. The two components were mixed thoroughly and small yellow crystals quickly formed. The contents were dried in vacuo then washed with diethyl ether and washed with acetone until colorless wash was obtained $(7 \times 15 \mathrm{~mL})$. Some of compound $\mathbf{1}$ will be converted to compound $\mathbf{2}$ during workup. However, in a separate experiment we have determined that compound $\mathbf{2}$ has very limited solubility in acetone, compared to compound $\mathbf{1}$. In order to selectively isolate compound 3 from potential mixture of compound $\mathbf{1}$ and compound $\mathbf{2}$, the mixture was washed with acetone. All of the acetone washes were combined and solvent was removed under reduced pressure. Dry solid yielded 33.9\% complex 1 .

Route 2: $0.0844 \mathrm{~g}(0.4 \mathrm{mmol})$ of $\mathrm{SnCl}_{2}$ was added to a round bottom flask along with $0.1203 \mathrm{~g}$ (1 mmol) 4-MA dissolved in $15 \mathrm{~mL}$ ethanol and mixed vigorously. The mixture was dried under vacuum then washed with diethyl ether to remove excess 4-MA. The remaining mixture was washed with acetone to isolate tin(II) complex. This acetone fraction was then dried under vacuum. Dry solid yielded 40.3\% complex 1; IR $\left(\mathrm{cm}^{-1}\right)$ 3333, 3247, 3158, 3047, 2921, 2851, 2745, 2585. 


\subsection{Synthesis of $\left[\mathrm{Sn}\left(4-\mathrm{SC}_{6} \mathrm{H}_{4} \mathrm{NH}_{2}\right)_{2}\left(4-\mathrm{SC}_{6} \mathrm{H}_{4} \mathrm{NH}_{3}\right)_{2} \mathrm{Cl}_{2}\right]$}

The tin(IV) complex (2) was prepared by two routes as well.

Route 1: A solution was prepared by dissolving $0.1003 \mathrm{~g}(0.2 \mathrm{mmol})$ of compound 1 in $10 \mathrm{~mL}$ of acetone. A gentle stream of air was bubbled through the solution for $12 \mathrm{~h}$. This method resulted in an impure product containing compounds 1 and 2.

Route 2: $0.0509 \mathrm{~g} \mathrm{SnCl}_{4} \cdot 5 \mathrm{H}_{2} \mathrm{O}(0.1 \mathrm{mmol})$ was combined with $0.0736 \mathrm{~g}(0.6 \mathrm{mmol})$ ethanolic 4-MA in a vial. A yellow solution forms and, upon further disturbance, small yellow crystals precipitate from solution. This mixture was dried under vacuum then washed with water $(3 \times 1 \mathrm{~mL})$, followed by further washing with acetone and diethyl ether. The dry solid yielded $64.2 \%$ of compound 2 . IR $\left(\mathrm{cm}^{-1}\right) 3332$, $3245,3158,3047,2825,2744,2585$.

\subsection{X-ray Crystallography}

A greenish yellow platelet crystal of compound 1 having dimensions of $0.29 \times 0.16 \times 0.03 \mathrm{~mm}$ and a yellow prism crystal of compound 2 having dimensions of $0.23 \times 0.15 \times 0.14 \mathrm{~mm}$ were attached to a MiTeGen (Ithaca, NY, USA) loop by Apiezon (Manchester, UK) grease and mounted on a Rigaku Mercury (The Woodlands, TX, USA) 375R/M CCD (XtaLAB mini) diffractometer using graphite monochromated Mo-Ka radiation $(0.71075 \AA)$ at $273 \mathrm{~K}$. The crystals were positioned at $49.50 \mathrm{~mm}$ from the CCD system. Data were collected and processed using Crystal Clear (Rigaku, The Woodlands, TX, USA). The data were corrected for Lorentz and polarization effects. The structures of both the complexes were solved using direct methods with SHELXS97 program [26]. The non-hydrogen atoms were refined with anisotropic thermal parameters. The hydrogen atoms were included in calculated positions (riding model) with $U$ iso set at 1.2 times the $U$ eq of the parent atom. The structures were refined on $F^{2}$ by full-matrix least-squares using SHELXL97 [26]. Crystallographic data for compounds 1 and 2 have been deposited with the Cambridge Crystallographic Data Centre (CCDC). The CCDC deposition number for compound $\mathbf{1}$ is 1009828 . The CCDC deposition number for compound $\mathbf{2}$ is 1027160 . This data can be obtained free of charge from www.ccdc.cam.ac.uk/data_request/cif.

\section{Conclusions}

A new one dimensional coordination polymer of tin(II) and 4-mercaptoaniline was synthesized by a simple procedure under ambient conditions. The compound was studied for structural insight. The tin center has a distorted trigonal pyramidal geometry, where one of the ligands coordinates in a terminal fashion, whereas, the other two ligands are bridging the tin centers in $\mu^{2}$ fashion, giving rise to one dimensional polymeric structure. The terminal ligand had the amine group protonated with a chloride counter anion. Upon treatment with oxygen this polymer oxidized to a mononuclear tin(IV) complex. The tin center for this complex has a tetrahedral geometry with two of the four ligands having protonated amine groups with chloride counter anions.

\section{Acknowledgments}

TAS acknowledges the partial support of this work by a grant from the US DOE, fund number 222174-13407. 


\section{Author Contributions}

Both authors contributed to all the sections of this article.

\section{Conflicts of Interest}

The authors declare no conflict of interest.

\section{References}

1. Osawa, M.; Matsuda, N.; Yoshii, K.; Uchida, I. Charge transfer resonance Raman process in surface-enhanced Raman scattering from $p$-aminothiophenol adsorbed on silver: Herzberg-Teller contribution. J. Phys. Chem. 1994, 98, 12702-12707.

2. Ho Choi, S.; Kim, B.; Frisbie, C.D. Electrical resistance of long conjugated molecular wires. Science 1994, 320, 1482-1486.

3. Johnson, S.R.; Evans, S.D.; Brydson, R. Influence of a terminal functionality on the physical properties of surfactant-stabilized gold nanoparticles. Langmuir 1998, 14, 6639-6647.

4. Zemlyanskii, N.N.; Borisova, I.V.; Kuznetsova, M.G.; Khrustalev, E.N.; Antipin, M.Y.; Ustynyuk, Y.A.; Lunin, E.E.; Eaborn, C.; Hill, M.S.; Smith, J.D. New Stable Germylenes, Stannylenes, and Related Compounds II. Bis(butylthio)tin(II) and ate-Complexes $\left[\left(\mathrm{Me}_{3} \mathrm{Si}\right)_{3} \mathrm{CE}(\mu-\right.$ $\left.\mathrm{SBu})_{2} \mathrm{Li}(\mathrm{THF})_{2}\right](E=\mathrm{Ge}, \mathrm{Sn})$. Synthesis and Structure. Russ. J. Org. Chem. 2003, 39, 491-500.

5. Jetti, R.K.R.; Boese, R.; Thakur, T.S.; Vangala, V.R.; Desiraju, G.R. Proton transfer and $\mathrm{N}^{(+)}-\mathrm{H} \cdots \mathrm{S}^{(-)}$ hydrogen bonds in the crystal structure of 4-aminothiophenol. Chem. Commun. 2004, 2526-2527.

6. Vidu, R.; Plapcianu, C.; Bartha, C. Multivalence Ce and Sn Oxide Doped Materials with Controlled Porosity for Renewable Energy Applications. Ind. Eng. Chem. Res. 2014, 53, 7829-7839.

7. Wang, H.; Rogach, A. Hierarchical $\mathrm{SnO}_{2}$ nanostructures: Recent advances in design, synthesis, and applications. Chem. Mater. 2013, 26, 123-133.

8. Tahar, R.; Ban, T. Tin doped indium oxide thin films: Electrical properties. J. Appl. Phys. 1998, 83, 2631-2645.

9. Barsan, N.; Schweizer-Berberich, M.; Gopel, W. Fundamental and practical aspects in the design of nanoscaled $\mathrm{SnO}_{2}$ gas sensors: A status report. Fresenius' J. Anal. Chem. 1999, 365, 287-304.

10. Barth, S.; Hernandez-Ramirez, F.; Holmes, J.D.; Romano-Rodriguez, A. Synthesis and applications of one-dimensional semiconductors. Prog. Mater. Sci. 2010, 55, 563-627.

11. Hamberg, C. Evaporated tin-doped indium oxide films: Basic optical properties and applications to energy efficient windows. J. Appl. Phys. 1986, 60, 123-159.

12. Singh, O.M.; Devi, L.R. Stannous chloride as a versatile catalyst in organic synthesis. Mini. Rev. Org. Chem. 2013, 10, 84-96.

13. Thomas, J.M.; Johnson, B.F.G.; Raja, R.; Sankar, G.; Midgley, P.A. High-performance nanocatalysts for single-step hydrogenations. Acc. Chem. Res. 2003, 36, 20-30.

14. Espinet, P.; Echavarren, A.M. The mechanisms of the Stille reaction. Angew. Chem. Int. Ed. Engl. 2004, 43, 4704-4734.

15. Sun, Y.F.; Lei, F.C.; Gao, S.; Pan, B.; Zhou, J.F.; Xie, Y. Atomically thin tin dioxide sheets for efficient catalytic oxidation of carbon monoxide. Angew. Chem. Int. Ed. Engl. 2013, 52, 10569-10572. 
16. Zhu, M.; Sun, G.; Xin, Q. Effect of alloying degree in PtSn catalyst on the catalytic behavior for ethanol electro-oxidation. Electrochim. Acta 2009, 54, 1511-1518.

17. Wu, J.; Risalvato, F.G.; Ma, S.; Zhou, X.-D. Electrochemical reduction of carbon dioxide III. The role of oxide layer thickness on the performance of Sn electrode in a full electrochemical cell. J. Mater. Chem. A 2014, 2, 1647.

18. Park, P.W.; Kung, H.H.; Kim, D.; Kung, M.C. Characterization of $\mathrm{SnO}_{2} / \mathrm{Al}_{2} \mathrm{O}_{3}$ Lean $\mathrm{NO}_{x}$ Catalysts. J. Catal. 1999, 184, 440-454.

19. Batzill, M.; Diebold, U. The surface and materials science of tin oxide. Prog. Surf. Sci. 2005, 79, 47-154.

20. Ozin, G. New directions in tin sulfide materials chemistry. J. Mater. Chem. 1998, 8, 1099-1108.

21. Eichhöfer, A.; Jiang, J. 1-D-Tin(II) Phenylchalcogenolato Complexes $\infty^{1}\left[\operatorname{Sn}(E \mathrm{Ph})_{2}\right](E=\mathrm{S}, \mathrm{Se}$, Te)-Synthesis, Structures, Quantum Chemical Studies and Thermal Behaviour. Eur. J. Inorg. Chem. 2010, 2010, 410-418.

22. Buttrus, N.H.; Suliman, M.M.; Al-Allaf, T.A.K. Synthesis of new Tin(IV) compounds of substituted diphenylsulfide derivatives and their complexes with some neutral ligands. Synth. React. Inorg. Met. Chem. 2001, 31, 837-848.

23. Wuyts, Y.; Vangindertaelen, A. The quadrivalence of tin and its mercaptides. Bull. Soc. Chim. Belg. 1921, 30, 323-328.

24. Almagro, X.; Clegg, W. Schiff bases derived from mercury (II)-aminothiolate complexes as metalloligands for transition metals. J. Organomet. Chem. 2001, 623, 137-148.

25. Wang, L.S.; Zhang, J.J.; Du, W.X.; Hu, S.M.; Fu, R.-B.; Xia, S.-Q.; Wu, X.-T.; Xiang, S.-C.; Li, Y.-M.; Fu, Z.-Y. Syntheses and characterizations of $\left(4-\mathrm{NH}_{2} \mathrm{C}_{6} \mathrm{H}_{4} \mathrm{~S}\right)_{4} \mathrm{Sn}$ and $\left[\left(4-\mathrm{NH}_{2} \mathrm{C}_{6} \mathrm{H}_{4} \mathrm{~S}\right)_{2}(4-\right.$ $\left.\left.\mathrm{NH}_{3} \mathrm{C}_{6} \mathrm{H}_{4} \mathrm{~S}\right)_{2} \mathrm{Sn}\right] \mathrm{Cl}_{2}$. Chin. J. Struct. Chem. 2005, 24, 79-83.

26. Sheldrick, G.M. A short history of SHELX. Acta Cryst. A 2008, 64, 112-122.

(C) 2014 by the authors; licensee MDPI, Basel, Switzerland. This article is an open access article distributed under the terms and conditions of the Creative Commons Attribution license (http://creativecommons.org/licenses/by/4.0/). 